\title{
Collective symbolic coping with disease threat and othering: A case study of avian influenza
}

\author{
Ingrid Gilles', Adrian Bangerter ${ }^{\text {** }}$, Alain Clémence ${ }^{2}$, \\ Eva G. T. Green ${ }^{2}$, Franciska Krings², Audrey Mouton ${ }^{2}$, \\ David Rigaud ${ }^{2}$, Christian Staerklé ${ }^{2}$ and Pascal Wagner-Egger ${ }^{3}$ \\ 'University of Neuchatel, Switzerland \\ ${ }^{2}$ University of Lausanne, Switzerland \\ ${ }^{3}$ University of Fribourg, Switzerland
}

\begin{abstract}
Much research studies how individuals cope with disease threat by blaming out-groups and protecting the in-group. The model of collective symbolic coping (CSC) describes four stages by which representations of a threatening event are elaborated in the mass media: awareness, divergence, convergence, and normalization. We used the CSC model to predict when symbolic in-group protection (othering) would occur in the case of the avian influenza (Al) outbreak. Two studies documented CSC stages and showed that othering occurred during the divergence stage, characterized by an uncertain symbolic environment. Study I analysed media coverage of Al over time, documenting CSC stages of awareness and divergence. In Study 2, a two-wave repeated cross-sectional survey was conducted just after the divergence stage and a year later. Othering was measured by the number of foreign countries erroneously ticked by participants as having human victims. Individual differences in germ aversion and social dominance orientation interacted to predict othering during the divergence stage but not a year later. Implications for research on CSC and symbolic in-group protection strategies resulting from disease threat are discussed.
\end{abstract}

Between 1347 and 1351, much of the European population died by the Black Death (Halioua, 2004). In desperation, physicians, religious authorities, and the common folk adopted various practices to ward off infection. Recommendations included burning incense, bathing in human urine, applying dried toads to lesions, or self-flagellation (Kelly, 2005). These practices reflected theories about the origins of the disease, some of which blamed Jews for poisoning wells. As a result, xenophobia emerged and Jews and other stigmatized groups were persecuted across Europe. For example, on 14 February 1349, inhabitants of Strasbourg killed 900 Jews from that city (Kelly, 2005).

\footnotetext{
* Correspondence should be addressed to Adrian Bangerter, Institute of Work and Organizational Psychology, University of Neuchâtel, Emile-Argand II, Neuchâtel 2000, Switzerland (e-mail: adrian.bangerter@unine.ch).
} 
This example illustrates two recurrent social phenomena associated with mass disease outbreaks: (1) a collective effort at making sense or symbolically coping (Wagner, Kronberger, \& Seifert, 2002) with the disease threat and devising means of protection, and (2) blaming and persecution of specific groups such as minorities or foreigners for the disease (Joffe, 1999). This example remains relevant today. Many studies have documented how disease threat leads to avoidance or stigmatization of out-groups (Joffe, 1999; Faulkner, Schaller, Park, \& Duncan, 2004). At least two prominent research traditions in social psychology have studied out-group blame and avoidance due to disease threat.

A social representations approach (Joffe, 1999) proposes that people make sense of disease threat by means of socially constructed beliefs. An important function of these beliefs is to symbolically protect the in-group by distinguishing it from the out-group (Turner, Hogg, Oakes, Reicher, \& Wetherell, 1987). The distinction is used to blame out-groups for causing or spreading disease, be it by a lack of hygiene (Joffe \& Lee, 2004; Washer, 2004), education or self-control (Joffe \& Staerklé, 2007), or by primitive sexual or cultural practices. Evidence of this process of symbolic othering (Joffe, 1999) can be found at many levels. Since the middle ages, the nation has been an important category for constructing otherness in terms of disease spread. This is evident in the way diseases are named. In the 15th century, syphilis was variously referred to as 'French pox' (by the English), morbus Germanicus (by the French), or 'Chinese disease' (by the Japanese) (Joffe, 1999; Sontag, 1989). Othering along national lines is also evident in the way cultural practices of other nations are depicted as an explanation for a disease. For instance, the Severe Acute Respiratory Syndrome (SARS) epidemic was described in the British media as being caused by unhygienic Chinese cultural habits, such as dirty markets, close proximity to animals, or the habit of spitting on the ground (Washer, 2004). The Ebola outbreak was also associated with Africa or African culture in the media (Joffe \& Haarhoff, 2002).

An evolutionary approach explains inter-group phenomena, especially prejudice and avoidance, as an evolved adaptation to protect individuals from disease threat (Faulkner et al., 2004; Kurzban \& Leary, 2001; Park, Faulkner, \& Schaller, 2003). Disease has always represented a threat to human survival. Consequently, humans evolved behavioural tendencies to avoid people likely to transmit diseases, such as out-group members. Because of the potentially high costs of infection, mechanisms have evolved to extend avoidance to generalized out-groups such as foreigners (Schaller, Faulkner, Park, Neuberg, \& Kenrick, 2004). Moreover, there exist individual differences in perceived vulnerability to disease and more particularly in people's aversion to germs (GA, Duncan, Schaller, \& Park, 2009). These individual differences predict negative attitudes towards immigrants (Duncan et al., 2009). In addition, the evolutionary approach has shown that contextually aroused perceptions of disease threat trigger xenophobic responses, even when the threat is unrelated to foreign out-groups (Faulkner et al., 2004; Navarrette \& Fessler, 2006). However, demonstrations of contextual effects typically rely on manipulation of disgust-evoking stimuli or disease salience and are unspecific as to when during an epidemic threat perceptions are likely to be high.

Taken together, research from both the social representations and evolutionary approaches demonstrate the ubiquity of the link between disease and out-groups, especially national out-groups, despite the existence of authoritative scientific discourses explaining the origin of infectious diseases through natural causes. However, less attention has been paid to collective symbolic coping (CSC) (Wagner et al., 2002) with disease threat. We argue that inter-group phenomena like othering are fed, at an 
ideological level, by mass media reporting of the disease and, at an individual level, by the uncertainty caused by the diffusion of information. To explore this process, we applied the model of CSC (Wagner et al., 2002) to the recent outbreak of avian influenza (AI).

\section{Collective symbolic coping: How people make sense of collective threats}

The CSC model (Wagner et al., 2002) describes how groups make sense of novel situations that threaten the social order. Anchored in social representation theory (Moscovici, 1988; Wagner \& Hayes, 2005), it emphasizes the collective dimension of the term coping (Lazarus \& Folkman, 1984). CSC involves the construction and diffusion of representations about a new collective threat, often through mass media. These representations provide individuals with ways of interpreting and dealing with the new threat. CSC occurs in four stages. First, during the awareness stage, the new situation emerges as an issue through media agenda setting (McCombs, 1981). Second, intensive communication leads to a divergence stage during which multiple frames or interpretations emerge, creating ambiguity, and uncertainty about origins of the new situation. In the third stage, convergence, a dominant discourse emerges that decreases uncertainty. In the fourth stage, normalization, the explanation of the event is integrated into common knowledge, becoming more mundane.

This model is useful for describing sense-making processes in the face of different threats to the social order. According to the few existing studies (Hibino \& Nagata, 2006; Wagner et al., 2002), increases in intensity of coverage and multiple interpretive frames are typical of the awareness and divergence stage (Hibino \& Nagata, 2006). Less is known about convergence and normalization. Convergence could be detected through decrease of media coverage and of inconsistent frames. But, normalization seems to be a complex, long-term process that can sometimes last for decades (Bauer, 1998).

The CSC model has only been studied for threat related to biotechnology. Here, we extend the model to the domain of emerging infectious diseases. These diseases represent not only a physical but also a symbolic threat to the social order (Joffe, 1999). For example, AIDS threatened many established ideas including the notions of safe and unsafe sexual practices (Joffe, 1999). It also seems plausible to assume that collective sensemaking of emerging infectious diseases evolves over time. For AIDS again, following its initial emergence in 1981 (i.e., awareness according to the CSC model), the disease was indeed characterized by multiple interpretations (i.e., divergence according to the CSC model). These included rumours (Kimmel \& Keefer, 1991), theories attributing blame to deviant groups such as gays, or conspiracy theories implicating governments (Goertzel, 1994) or scientists (Joffe \& Bettega, 2003). Since the mid-1980s, an official public discourse on AIDS has emerged in Anglo-Saxon countries (Adam, 1989; Joffe, 1999), suppressing other deviant discourses such as denialism (Kalichman, 2009). The emergence of an official discourse corresponds to the convergence stage of CSC. Finally, AIDS is in a process of normalization since 1996 (Rosenbrock et al., 2000), characterized by banalization in public discourse, and decreased perception of threat - also consistent with the normalization stage of the CSC model.

In this paper, we document awareness and divergence stages of CSC relative to the AI outbreak. These stages are characterized in the media by an increase of coverage for the awareness stage, and a multiplicity of frames, or themes, that induce ambiguous or uncertain perspectives on events, during the divergence stage. In the case of AI, the pandemic failed to materialize, and no consensual explanation emerged about its origins, modes of transmission, and protection against it, possibly increasing uncertainty 
and suspicion about potential man-made causes of the disease (Wagner-Egger et al., 2011). We therefore surmise that the divergence stage, by creating multiple discourses about AI and thus multiple interpretive frames, could cause a feeling of uncertainty in individuals that is reduced by out-group differentiation processes.

\section{Uncertain disease threat and out-groups: Othering as symbolic coping}

Some stages of CSC (mainly the divergence stage), by creating uncertainty, trigger an increased need for symbolic protection against the threatening event. Uncertainty favours the emergence of coping strategies like othering. This idea is supported by the subjective uncertainty reduction model (Grieve \& Hogg, 1999; Hogg, 2000) derived from self-categorization theory (Turner et al., 1987). This model states that reducing uncertainty and sensemaking are two strong motivations in people's life. Uncertainty is an aversive state (Mullin \& Hogg, 1999) reducing the perception of personal control and enhancing negative feelings such as fear. Uncertainty arises when people perceive disagreements and dissensus in their group. People try to reduce uncertainty by accentuating group identification or increasing inter-group differentiation (Hohman, Hogg, \& Bligh 2010; Mullin \& Hogg, 1999; Reid \& Hogg, 2005). The subjective uncertainty reduction model can thus specify the CSC model. The divergence stage of CSC is typically characterized by ambiguity and uncertainty due to multiple interpretive frames. We therefore hypothesize that inter-group differentiation strategies like othering are more likely to arise in this stage than others.

However, the relation between uncertainty about disease risk and othering may not always be direct because individuals vary in their chronic feelings of uncertainty. The relation may depend on individual differences in feelings aversion to germ as well as ideological beliefs. For example, germ aversion (GA) (Duncan et al., 2009) predicts implicit cognitions about out-groups and danger. Thus, people high in GA should react to uncertainty by manifesting more othering than people less aversive to germs. Social dominance orientation (SDO; Sidanius \& Pratto, 1999) is an ideological belief characterized by support for group-based hierarchical differences in society. Individuals high in this belief can be expected to tend to reinforce the symbolic distinction between subordinate germ-carrying out-groups and the dominant - clean and healthy - in-group members (Joffe \& Staerklé, 2007) in case of uncertain disease risk.

In summary, we suggest that othering is more likely to occur when mass media coverage of the disease is the highest and when multiple representations of the disease create uncertainty, that is, during the divergence stage of CSC. According to the subjective uncertainty reduction model, people try to reduce uncertainty by increasing inter-group differentiation strategies like othering in the case of disease threat. But, this strategy should be reinforced by chronic individual differences in GA and ideological beliefs such as SDO.

\section{Our studies}

Our research is grounded in AI, described by the World Health Organization (WHO) as one of the most dangerous emerging infectious diseases of the 21st century (http://www.who.int/csr/disease/avian_influenza/avian_faqs/en/index.html\#prepared, 21 January 2010). The H5N1 strain is a particular challenge for global public health because it has crossed the species barrier and may mutate, provoking a pandemic. Although animal-human and human-human transmission is currently limited, AI represents a major threat due to its high mortality (approaching 60\% as of June 2009 , 
http://www.who.int/csr/disease/avian_influenza/country/cases_table_2009_07_01/en/ index.html, 21 January 2010). Since 1997, several outbreaks of H5N1 have occurred (2003 and 2004) in Asian countries such as Vietnam, Thailand, or Indonesia. In July 2005, the virus spread to Europe. We studied the period following initial infections in birds in Europe, from September 2005 onwards.

As an emerging infectious disease, AI represents a new material and symbolic threat the public needed to cope with. We conducted two studies. In Study 1, we extended the CSC model to AI by analysing media coverage about the disease between Fall 2005 and late Spring 2007. The model predicts an initial increase in media coverage of AI (awareness stage), then more thematic diversity in coverage (divergence stage) followed by a decrease in coverage and thematic diversity (convergence stage). Given that the normalization stage could take years, we had no expectations about this stage for AI.

In Study 2, we link uncertainty occurring during the divergence stage of the CSC with othering. We measured othering tendencies in a two-wave repeated cross-sectional survey, with Wave 1 in June 2006 (just after the divergence stage observed in Study 1) and Wave 2 in June 2007. Comparing othering between Waves 1 and 2 creates a natural control for the effect of the awareness stage of CSC on othering. We also analysed the moderating impact of GA and SDO on othering at both waves. We operationalized othering by asking respondents to indicate whether countries had experienced human cases of AI (none of the countries had). Assigning human cases to foreign countries can be interpreted as a way of distancing oneself from such countries and its inhabitants, labelling them as 'contaminated'. We expect that at Wave 1, uncertainty would particularly affect participants high in GA and in SDO and would induce them to generalize AI to foreign countries, that is, to assign more human cases of AI to foreign countries than participants low in GA and SDO. This should not be the case at Wave 2, when uncertainty had decreased.

\section{STUDY I: AI IN THE MEDIA}

Study 1 investigated the time course and textual structure of media coverage of AI between September 2005 and June 2007. The time course analysis measured fluctuations in AI coverage. Text analysis explored the topical diversity of coverage over time, diversity being an indicator of multiple approaches of the disease and thus of divergence. Taken together, these analyses allow us to document CSC stages (Wagner et al., 2002).

\section{Method}

\section{Materials}

One hundred and seventy-eight articles (total word count 31,094) were selected from the Lexis-Nexis database. The selection was restricted to articles published on AI (key words in French: grippe aviaire, transmission, and propagation) in 20 French-speaking European newspapers or press agencies between September 2005 and June 2007. We also restricted the search to articles about five main geographical areas concerned by AI: Africa, Asia, Eastern Europe, Middle East, and Western Europe. Multiple instances of the same article were eliminated.

We first analysed the time course of media coverage, that is, the number of articles published each month between September 2005 and June 2007. We then conducted a 
computer-assisted text analysis using the Alceste software package (Reinert, 1996) on the 178 articles, identifying discourse classes and their associations with specific temporal periods.

\section{Computer-assisted text analysis}

Following the CSC model, we expected temporal changes in the thematic diversity of media coverage of AI. To avoid problems associated with reliability and validity of classical content analyses, in particular coding biases (Bauer, 2000; Klein \& Licata, 2003; Schonhardt-Bailey, 2005), we applied automatic textual classification to the corpus using Alceste. The software first creates a reduced dictionary after lemmatizing words (reducing words to their roots, e.g., vaccine or vaccination are lemmatized to vaccin + ). Conceptual words (nouns, verbs, adjectives, adverbs) with a minimum frequency (four by default) are active words in the analysis and are separated from passive words such as articles or connectors. The first step of the analysis is segmenting texts into socalled Elementary Contextual Units (ECUs) corresponding approximately to one or two sentences (approximately 30-50 words; Kronberger \& Wagner, 2000). ECUs are then grouped into a number of classes using the co-occurrences between active words. A class must contain at least $5 \%$ of ECUs. To check the validity of the classification, two hierarchical descending cluster analyses are then conducted by changing the number of active words per ECU. If the two analyses reveal a similar pattern of clusters, a final classification is built by retaining the overlapping ECUs of both clusters and excluding the others. This is the main product of the Alceste analysis. Interpretation of the results, that is, naming the classes, is guided by the words and ECUs significantly associated with each class. The strength of the typical words and ECUs of each class is determined by a chi-square statistic, estimating the deviation of the word's frequency in a class from a random distribution of all words among all classes (Schonhardt-Bailey, 2005). One then obtains a specific dictionary of the typical (more frequent than expected by chance) and anti-typical words (less frequent than expected by chance) for each class. Alceste also identifies typical ECUs of a class.

Finally, Alceste allows to examine the link between classes and the modalities of passive variables characterizing each text. In our case, publication date (month and year) as well as the name of the newspaper was introduced as passive variables. Each article is entered with its publication date and the name of the newspaper it was published in, so that each ECU of the article is associated with this information. A chi-square statistic is also calculated to estimate the deviation from a random distribution of the associations between each modality with each class.

\section{Results}

\section{Time course analysis}

Figure 1 shows the time course plots. Two main peaks appear, first in October 2005, and then in February 2006. From March 2006, coverage decreases and remains constant until June 2007 except for a small third peak in February 2007.

The first peak corresponds to reports about the arrival of infected birds in Europe. The second peak corresponds to reports about the discovery of AI in an increasing number of European countries (at the time, cases of $\mathrm{H} 5 \mathrm{~N} 1$ in wild birds spread through Europe and infected poultry). Even if $\mathrm{H} 5 \mathrm{~N} 1$ has been known since 2003 for its serious consequences for animals and humans, it was limited to Asian countries. In October 2005, 


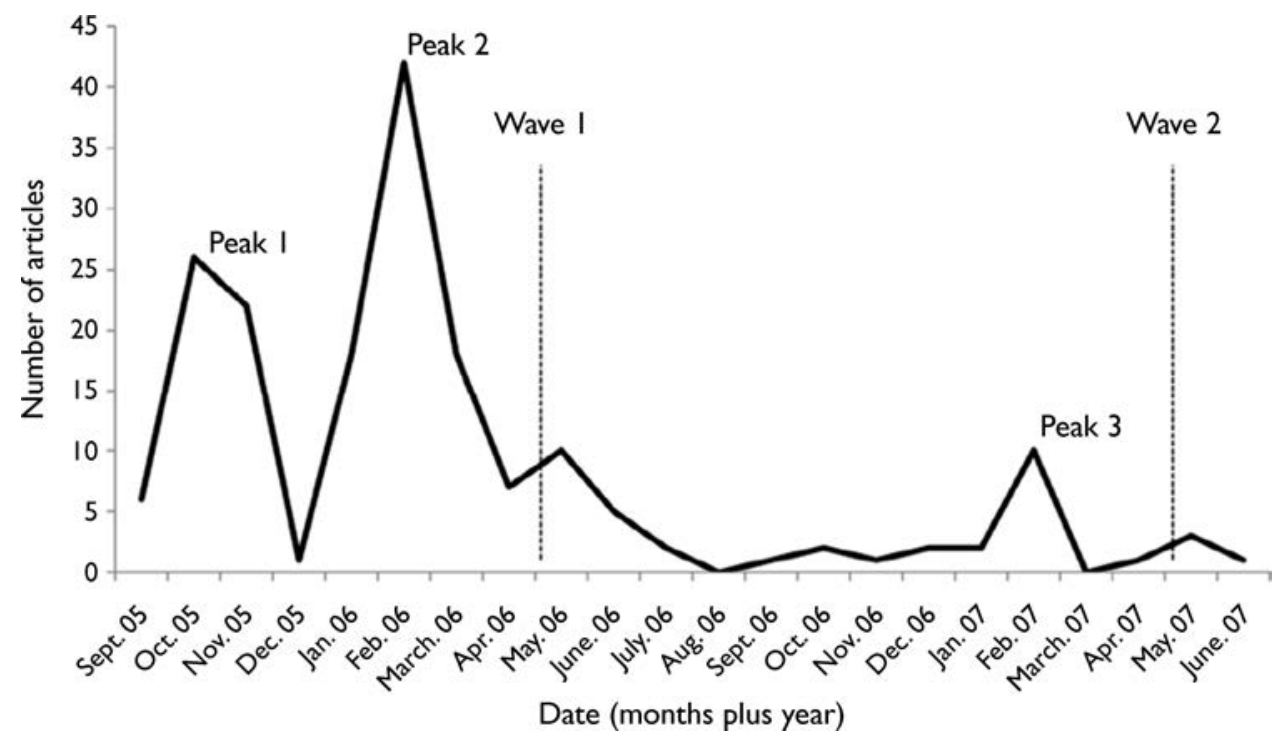

Figure I. Time course of media coverage of avian influenza, September 2005 to June 2007. Peaks in coverage and the two waves of Study 2 are also indicated.

the WHO confirmed first animal cases of H5N1 in Turkey, Romania, and the United Kingdom (http://www.who.int/csr/disease/avian_influenza/ Timeline090727.pdf). So, the first peak in Figure 1 corresponds to the awareness stage of CSC, during which a novel event acquires widespread relevance through media amplification (Wagner et al., 2002). The second peak could constitute the divergence phase, characterized by more coverage, and an increase of thematic diversity. Finally, the decrease and stabilization of coverage between May 2006 and June 2007 could constitute a convergence stage. The last (much smaller) peak in February 2007 corresponds to the emergence of some new cases of AI among wild birds and poultry in Europe, mainly in Great Britain and so to a reactivation of threat about $\mathrm{AI}$.

\section{Textual analysis: Descriptions of classes}

The time course data are not, in itself, a demonstration that media coverage of AI followed CSC stages. The text analysis provides more evidence. Alceste identified 1,347 different active word types with a minimal frequency of seven, representing a total of 45,488 words distributed in 2,981 ECUs. The hierarchical descending cluster analysis classified 2,143 ECUs ( $71.9 \%$ of the corpus) into six classes after a first differentiation between two clusters, one composed of two and the other of four classes. We named the classes based on their most typical words and ECUs. Table 1 presents a summary of the results in terms of each class and its typical words, anti-typical words and typical ECUs.

The two classes of the first cluster concern reports on actions of international organizations and governments to face a disease outbreak. Class 1 (25.7\% of classified ECUs) was named Medical coping strategies. It describes how countries would take steps to check a potential outbreak by constituting stocks of vaccines or buying medicine from pharmaceutical firms. Numerous action verbs (e.g., protect, plan, coordinate) describe intense activity of governmental health agencies to organize prevention and protection of the population. Class 2 was named International financial strategies 


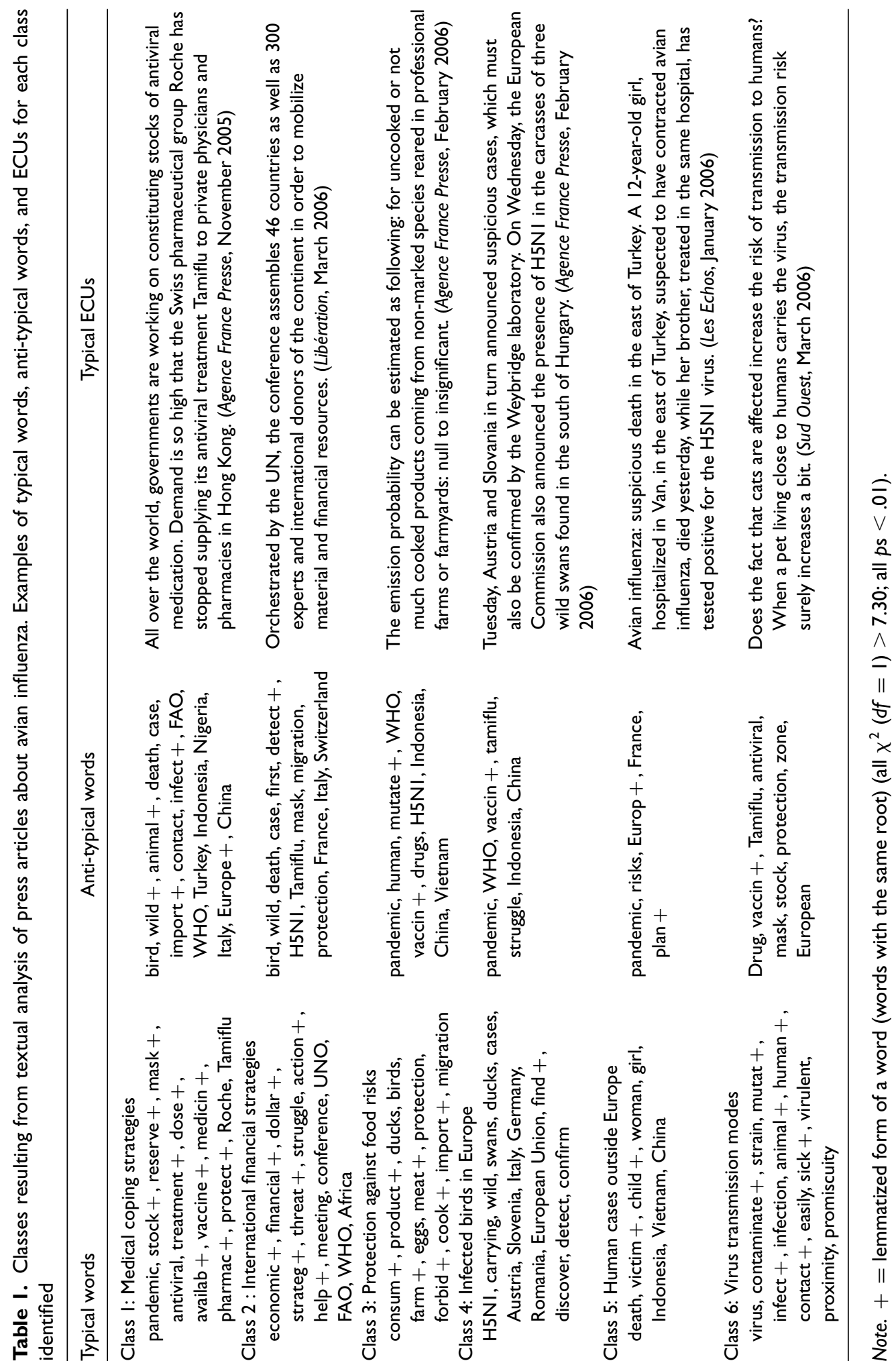


(22.8\% of classified ECUs). It describes $\mathrm{AI}$ as an international problem that countries have to mobilize against via financial and economic actions designed to collect funds for international organizations. Typical ECUs describe conferences where leaders and experts of these organizations emphasize the need for financial means to face the disease and to help poor countries, in particular African countries such as Nigeria and Niger. Discourse in these classes does not evoke the factual and concrete aspects of AI, which constitute the essential content of the other four classes.

The repeated announcement by the WHO of the threat of a pandemic is significantly less frequent among all classes of the second cluster, as are evocations of medical coping. Class 3 concerns measures imposed by authorities to protect farms and to prevent disease transmission through migrating birds or food consumption. We labelled it Protection against food risks (18.8\% of classified ECUs). The content is organized around the control of farmyards and ornithological parks imposed by authorities in different geographical areas of European countries. The population is encouraged to adopt safety rules (e.g., cooking meat, avoiding wild ducks). Few references are made to cases of infected animals.

The opposite is true for Class 4 named Infected birds in Europe (10.8\% of classified ECUs). Content focuses on cases of wild birds infected by H5N1 and found dead in both Western (Germany, Austria, France, Italy, and Spain) and Eastern (Croatia, Hungary, Romania, Slovenia, and Bulgaria) Europe. The information appears as precise reports about the type and the number of birds infected, as well as the locations and the dates of their detection.

In a similar but more dramatic vein, Class 5 was named Human cases outside Europe (9.1\% of classified ECUs). Typical ECUs enumerate victims of AI in four countries (Indonesia, Vietnam, China, and Turkey) and also evoke other Asian Countries (Thailand, Cambodia, Japan, Korea, Mongolia, Malaysia, and Iran). They report the characteristics of the victims and the circumstances of the diagnosis of symptoms.

Class 6 was named Virus transmission modes (12.9\% of classified ECUs) and concerns transmission of AI from animals to humans, focusing on living conditions of people in Asian countries. Different paths of contamination are discussed depending on possible virus mutations. There are also references to the probability of contamination due to proximity between infected animals and humans, as in families of Asian victims.

\section{Textual analysis: Association with temporal periods}

At this point, results show that newspapers cover a wide range of topics from the simple count of dead birds in Europe, to the elaboration of financial strategies to face a disease outbreak. Linking these results and CSC stages requires an analysis of the association between classes and temporal periods. Table 2 presents the distribution of the ECUs by class and by month between September 2005 and May 2007. On the basis of this distribution, Alceste computes signed chi-square tests with one degree of freedom indicating, for each month, significant presence (in bold, Table 2) or significant absence (in italics, Table 2) of classes (critical $p$-value of .05).

In the autumn months of 2005, media coverage is dominated by an official discourse of medical experts about coping with the imminent disease outbreak (Class 1, significantly associated with September, October, and November 2005). Coverage decreases in December 2005. In January, February, and March 2006, we observe increases of all classes except Class 1. This starts with reports on human victims in Asia and issues of virus transmission (Classes 5 and 6) in January, continuing with infections of birds in 


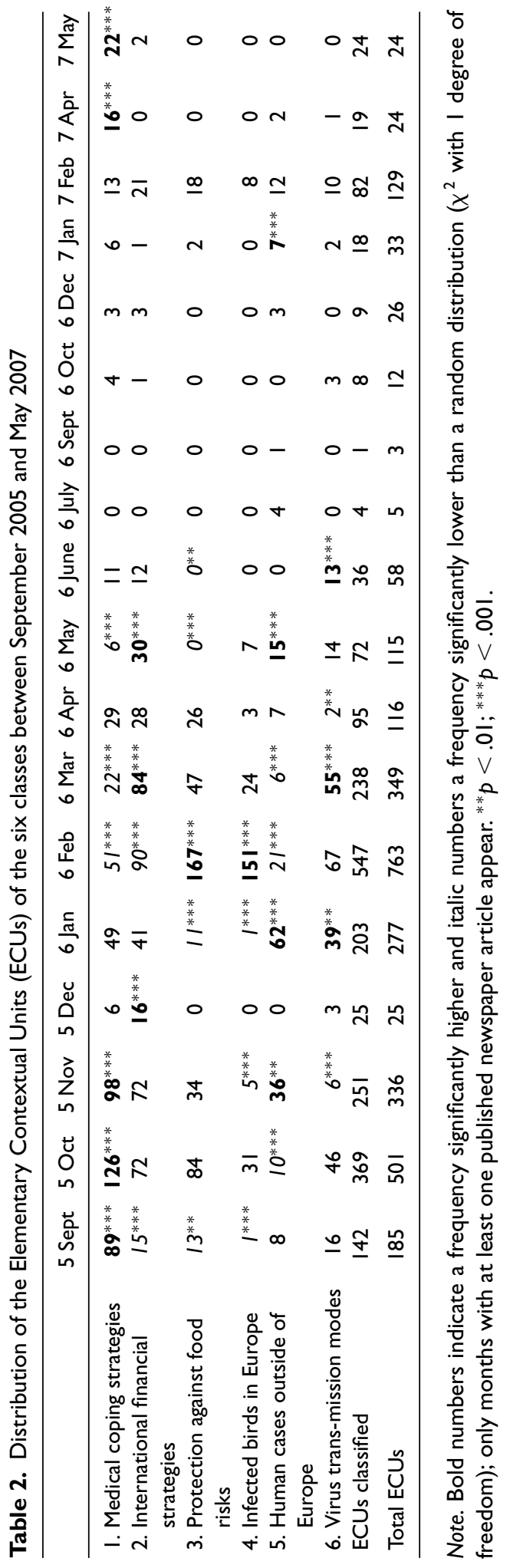


Europe and protection measures against food contamination in February (Classes 3 and 4) and ending with international funding in March (Class 2). These data suggest that thematic diversity increased during the second peak in media coverage from January to March 2006. We also observe a rapid decline of all classes until the last small peak in February 2007 following the announcement of new human victims. Only Class 1 is present at the end of the time course (April and May 2007). The message about pharmaceutical measures against an outbreak remained but was treated with skepticism in the rare newspapers still reporting on AI.

\section{Discussion}

Taken together, our results suggest that the awareness and divergence stages described by Wagner et al. (2002) can be documented for the 2005-2007 AI outbreak. Awareness appears when the problematic event first emerges in media discourse. Our evidence of this stage comes from the first peak between September and December 2005. The media discourse translates concerns derived from expert opinion. It remains abstract, without reporting about concrete aspects or effects of AI. Divergence is characterized by high media coverage and emergence of discussions and debate reflected in a multiplicity of topics. In our data, a second peak appeared between January and March 2006. The discourse becomes more concrete and varied by reporting recommendations for avoiding food contamination (Class 3), factual descriptions of human and animal AI victims (Classes 4 and 5), and related issues such as transmission (Class 6), while retaining a focus on international financial issues (Class 2). The presence of these classes shows that the issue of AI became considerably more complex during this period. From this evidence, we conclude that the period between January and March 2006 corresponds to a divergence stage. There is little evidence for a convergence stage. It seems that when a tangible threat failed to materialize, the media simply stopped covering AI. However, we observed that Class 1 , medical coping strategies, remains the only theme present at the end of the period we analysed. Finally, we note that words, such as death, worried, security, safety, or risks, are associated with classes linked with the January to March 2006 period.

Our findings have an important limitation. The temporal dynamics we take as evidence for divergence could be a side effect of increased coverage of a topic in general (reflecting an increase of knowledge about that topic), rather than a specific effect of threat in particular. More research is needed to deal with this issue, which we expand upon in the General Discussion. However, increased knowledge about an unfamiliar topic may be viewed as being, in and of itself, threatening, because such novel knowledge creates uncertainty and needs to be integrated in common sense. In this way, it is the emergence and coexistence of multiple discourses about a topic that creates uncertainty and thus threat, and not only the content of the knowledge. That is why we expect the divergence stage to lead to an increase in uncertainty and individuals' perceptions of threat in early 2006 and to the mobilization of inter-group beliefs to cope with it. We investigated this in Study 2.

\section{STUDY 2: CSC STAGES, THREAT PERCEPTION, AND OTHERING}

Study 2 explored links between the uncertainty occurring during the divergence stage and othering. We conducted a two-wave repeated cross-sectional survey. Wave 1 took place in June 2006 at the end of the peak of media coverage (identified in Study 1 
as the divergence phase). Wave 2 took place in June 2007 when media coverage had decreased.

We measured othering in terms of the generalization of threat to national out-groups, that is, the number of foreign nations perceived as afflicted with human cases of AI. Participants indicated that countries, from a list of 15 countries from five geographic regions (the Middle East, Africa, Asia, Eastern Europe, and Western Europe), had experienced human cases of $\mathrm{H} 5 \mathrm{~N} 1$. The geographic regions were identical to those included in Study 1. Furthermore, countries were chosen according to two criteria: (1) they had documented cases of AI in birds that varied in media coverage, and (2) they had not experienced human cases. Thus, participants' choices reflected their knowledge of information diffused by media about countries and their representation of the geographical boundaries of AI spread. Indeed, as Study 1 showed, the media often depicted the spread of AI in terms of foreign nations. Moreover, media representations of the spread often used maps as visual aids. Geographical location thus constitutes an objectification (Wagner \& Hayes, 2005) of disease threat, that is, as a symbol of threat coming from outside.

As shown in Study 1, the divergence stage (January to May 2006) is characterized by an increase of information on the geographic evolution of victims of AI (animals and humans), the proximity of the danger and the unsolved question of the virus transmission from animals to humans. People are thus subject to an uncertain symbolic context that should facilitate othering reactions. We expected that during this divergence phase (Wave 1), people should tick more foreign countries on average when they are more aversive to germs. Moreover, the othering process should increase when the GA is coupled with a high endorsement of a hierarchical view of society (SDO). After the divergence stage (Wave 2), high SDO and high GA should not lead to more foreign countries being ticked. We thus expected a three-way interaction between Wave, SDO, and GA on the mean number of foreign countries ticked.

In Study 2, we also checked that participants are sensitive to the prevailing media context, and, at the same time, that the effects of our independent variables on othering are not simply artefacts of media coverage. Indeed, participants can be expected to tick countries that are frequently mentioned in the media more often than countries that are not, simply because such countries are better available in memory (Tversky \& Kahneman, 1973). We thus distinguished different measures of othering as a function of whether countries were frequently mentioned in the media or not. We expect the above-mentioned three-way interaction between Wave, GA, and SDO to hold especially for countries less frequently mentioned in the media.

\section{Method}

\section{Participants and procedure}

Four hundred and forty-two Swiss students (recruited in four French-speaking Swiss universities - Geneva, Lausanne, Neuchâtel, Fribourg - from various disciplines) were surveyed on a voluntary basis on their perceptions of AI. One hundred and ninety-three answered in June 2006 and 249 in June 2007. Mean age was 22.3 years $(S D=4.6)$ and $71.5 \%$ of the sample were women.

\section{Measures}

To assess GA, we used the relevant subscale of the Perceived Vulnerability to Disease (PVD) scale (Duncan et al., 2009). GA is negatively linked with pro-immigrant attitudes 
(Duncan et al., 2009). Moreover, it interacts with ideological orientations (such as SDO) to determine out-group avoidance phenomenon as a reaction to disease threat (Green et al., 2010). Participants completed a short version (three items) of the GA subscale (e.g., It really bothers me when people sneeze without covering their mouths; $\alpha=$ .64). A mean score was computed on the items and subsequently centred. Higher scores indicate more GA.

We measured SDO via a six-item scale drawn from Pratto, Sidanius, Stallworth, \& Malle (1994) $(\alpha=.86)$. A mean score was computed on the items and subsequently centred. Higher scores indicate higher SDO.

The othering dependent variable was computed from a list of 15 countries from five regions (Zimbabwe, Kenya, and Senegal for Africa; Japan, Malaysia, and the Philippines for Asia; Albania, Bulgaria, and Slovakia for Eastern Europe; Iran, Syria, and Saudi Arabia for the Middle East; Spain, Norway, and Austria for Western Europe). Participants ticked countries they believed to have experienced human cases of $\mathrm{H} 5 \mathrm{~N} 1$ infection $(M=$ 3.26 countries, $S D=1.99$ ). In fact, none of the countries had actually experienced human cases. Four othering indicators were constructed by dividing the 15 countries into four groups on primarily geographical grounds and calculating the mean rate at which countries in each group were ticked. The Asian group comprised Japan, Malaysia, and the Philippines $(M=0.57, S D=0.31)$, and the African group comprised Kenya, Senegal, and Zimbabwe $(M=0.14, S D=0.27)$. The nine remaining European and Middle Eastern countries were divided into those frequently mentioned in the media (based on Study 1), namely Austria, Bulgaria, Iran, and Spain $(M=0.14, S D=0.20)$, and those infrequently mentioned, namely Albania, Norway, Saudi Arabia, Slovakia, and Syria $(M=$ $0.07, S D=0.15$ ). This division was done because preliminary analysis showed that the ticks participants gave these countries in Waves 1 and 2 correlated with their media mentions in Study 1.

\section{Results}

Participants indicated their age, gender, preoccupations about AI, and university affiliation. Preoccupations about AI were measured through three items (e.g., How frequently do think about AI?, $\alpha=.69$ ) that were subsequently averaged. Age, gender, and preoccupations did not affect the dependent variables, nor did they interact with the predictors. They were thus removed from analyses. University was entered as a control (three dummy variables) in the analyses. The dummy variables did not interact with predictors for all indicators except for Africa. For this measure, university, GA, SDO, and wave interacted (four-way interaction). We thus do not interpret analyses for Africa and we removed the dummy university variables in the analyses of the three remaining othering measures.

The same multiple linear regressions were conducted on the three dependent variables (Table 3) with SDO, GA, Wave, and their interactions as predictors. Before performing analyses, we checked that GA and SDO did not vary as a function of Wave $(\mathrm{GA}: F(1,451)=0.13, n s ;$ SDO: $F(1,452)=2.03, n s)$.

For the othering score of Asian countries, only the effect of Wave was significant. As mentioned above, participants ticked more Asian countries at Wave 2 than at Wave 1.

For frequently mentioned countries, there was a significant interaction between SDO and GA, indicating that participants high in GA ticked more countries, but only when they were high in SDO $(B=0.043, S E=0.015, p<.01$; for people low in SDO, $B=$ $-0.015, S E=0.016, n s)$. The interaction between GA and Wave is also significant, 
Table 3. Multiple regression parameters for the perceived occurrence of avian influenza in Asia and in countries frequently and less frequently mentioned in newspapers as a function of wave, germ aversion, and social dominance orientation

\begin{tabular}{|c|c|c|c|c|c|c|}
\hline & \multicolumn{2}{|c|}{ Asia } & \multicolumn{2}{|c|}{$\begin{array}{l}\text { Frequ. Ment. } \\
\text { Countries }\end{array}$} & \multicolumn{2}{|c|}{$\begin{array}{c}\text { Less Frequ. Ment. } \\
\text { Countries }\end{array}$} \\
\hline & B & $S E$ & B & $S E$ & B & SE \\
\hline Intercept & $.562^{* * *}$ & .015 & $.132^{* * *}$ & .010 & $.063^{* * *}$ & .007 \\
\hline Wave & $.109^{* * *}$ & .030 & $.039 *$ & .019 & .014 & .014 \\
\hline SDO & .015 & .023 & .014 & .011 & .017 & .011 \\
\hline GA & .002 & .017 & -.003 & .014 & $.022^{* *}$ & .008 \\
\hline Wave $\times$ SDO & -.026 & .045 & .017 & .029 & -.017 & .022 \\
\hline Wave $\times$ GA & .008 & .034 & $-.058^{* *}$ & .022 & $-.050^{* *}$ & .017 \\
\hline $\mathrm{SDO} \times \mathrm{GA}$ & -.025 & .025 & $.042^{* *}$ & .016 & $.031^{*}$ & .012 \\
\hline Wave $\times$ SDO $\times \mathrm{GA}$ & .052 & .050 & $-.060+$ & .032 & $-.049 *$ & .024 \\
\hline$R^{2}$ & \multicolumn{2}{|c|}{$.037^{*}$} & \multicolumn{2}{|c|}{$.042^{* *}$} & \multicolumn{2}{|c|}{$.066^{* * *}$} \\
\hline
\end{tabular}

Note. GA $=$ germ aversion; SDO $=$ social dominance orientation. ${ }^{*} p<.05 ;{ }^{* *} p<.0 \mathrm{I} ;{ }^{* * *} p<.00 \mathrm{I}$; $+p<.10$.

showing that the impact of Wave was not significant for people high in GA $(B=-0.011$, $S E=0.027, n s)$ but was significant for people low in GA, who ticked more countries at Wave 2 than at Wave $1(B=0.091, S E=0.027, p<.001)$. These effects were qualified by the marginally significant expected three-way interaction between Wave, SDO, and GA. As expected, the interaction between SDO and GA was significant only at Wave 1 $(B=0.072, S E=0.027, p<.01)$. Slope tests indicated that for people high in GA, SDO had a marginal impact on ticked countries $(B=0.052, S E=0.03, p<.10)$. For people low in GA, SDO significantly decreased the number of countries ticked $(B=-.075, S E=$ $.036, p<.05)$. The interaction between SDO and GA did not hold at Wave 2: $(B=0.012$, $S E=0.017, n s)$.

For less frequently mentioned countries, there was a significant main effect of GA, indicating that people high in GA ticked more countries than those low in GA. A significant GA by SDO interaction indicated that GA increased the number of ticked countries, but only for participants high in SDO $(B=0.044, S E=0.011, p<.001)$ and not for participants low in SDO $(B=0.001, S E=0.012, n s)$. The GA by Wave interaction was significant, showing that the impact of Wave was not significant for people high in GA $(B=-0.030, S E=0.021, n s)$ but was significant for people low in GA, who ticked more countries at Wave 2 than at Wave $1(B=0.058, S E=0.020, p<.01)$. The expected three-way interaction (Figure 2) was significant and showed that the interaction between SDO and GA was only significant at Wave $1(B=0.055, S E=0.020, p<.01)$ and not at Wave $2(B=0.006, S E=0.013, n s)$. Slope tests indicated that for people high in GA, SDO significantly increased the number of ticked countries $(B=0.074, S E=0.023$, $p<.01)$. On the contrary, for people low in GA, SDO had no impact on the number of countries ticked $(B=-0.023, S E=0.027, n s)$.

\section{Discussion}

Study 2 aimed at extending past results about disease threat perceptions and othering, predicting the temporal occurrence of othering using the CSC model. We measured 


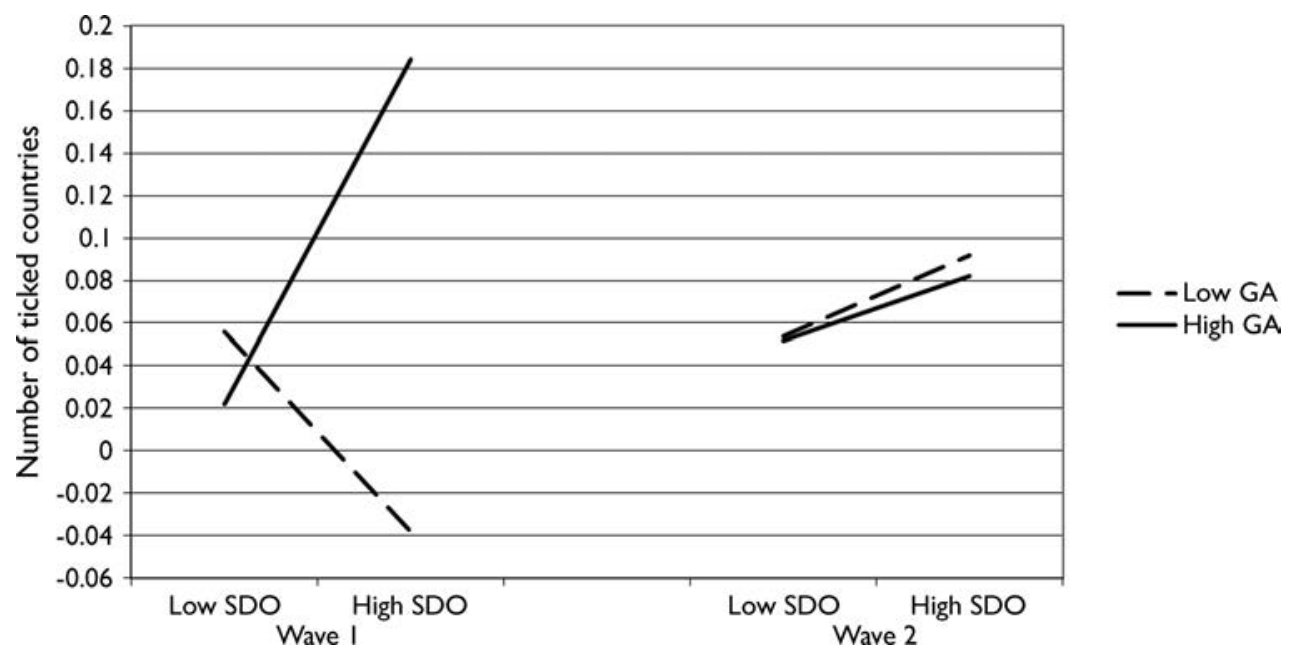

Figure 2. Mean estimated number of countries less frequently mentioned in newspapers that were perceived as being infected by human cases of $\mathrm{H} 5 \mathrm{NI}$, as a function of Wave, Germ Aversion, and Social Dominance Orientation.

Note. The graph was obtained by solving the regression equation, using mean values \pm I SD for high/low SDO and high/low GA.

othering by the mean number of foreign countries of different regions perceived as having experienced human cases of AI. Controlling for the frequency with which countries were mentioned in the media, we found that othering was higher during Wave 1 than Wave 2, but only for participants high in GA and SDO. Moreover, we observed this effect was stronger for countries less frequently mentioned by the media. This finding supports our claim that the divergence phase of CSC creates uncertainty that people try to reduce via out-group blame processes like othering.

For Asian countries, only Wave affected othering. This suggests that (erroneous) perceptions of human infections in these countries are directly tied to the media climate prevalent just before Wave 1, that is, the divergence phase, and were reinforced during the time following this phase. Note that Asia is the only region where participants do not differentiate the countries by taking into account their frequency of mention in newspapers. We note that this geographic area was mentioned more often in the newspapers in Study 1 than the others (478 citations of an Asian country against 301 for Western Europe, 189 for Eastern Europe, and 162 for the Middle East). Actually, $86 \%$ of participants ticked at least one Asian country compared with $18 \%$ for Western Europe, 32\% for Eastern Europe, and 13\% for Middle East. Thus, participants apparently perceived less ambiguity concerning Asia than concerning other geographical areas.

An unexpected result emerged from the marginally significant three-way interaction on the frequently mentioned countries. SDO marginally reinforced othering among people high in GA, but significantly decreased the number of ticked countries for people low in GA. This result could reveal that participants with high SDO use less media information in their judgment (a similar explanation has been proposed for authoritarian people concerning political knowledge, Peterson, Duncan, \& Pang, 2002) and consequently react to uncertainty by minimizing the danger in foreign countries when they are low in GA and exaggerate it when they are high in GA. Indeed, differences 
between the numbers of more and less frequently mentioned countries ticked tended to decrease at Wave 1 when SDO increased, as shown by an additional regression analysis on this score $(B=-0.037, S E=0.020, p=.062)$.

Except for Asia, interactions between GA and Wave and between SDO and GA were significant irrespective of how often countries were mentioned in the media. These interactions suggest that both evolved and cultural processes are not independent of each other but interact as part of a more global process (Krings et al., in press). Finally, they feed the debate around the idea that purportedly evolved individual differences, such as GA, are context dependent to some degree. Finally, results showed that both contextual conditions and ideological preferences are necessary for people to perceive a disease threat as coming from 'outside' (Joffe, 1999).

\section{GENERAL DISCUSSION}

Social psychologists have studied individual-level out-group blame and avoidance processes involved in coping with disease threat (Faulkner et al., 2004; Green et al. 2010; Joffe, 1999; Krings et al., in press). The CSC model offers a complementary perspective, describing stages by which public discourse leads to a collective representation of a threat (Wagner et al., 2002). But, it does not explain how these stages affect individual-level processes, in particular how the symbolic environment activates collective beliefs leading to inter-group phenomena like othering. The results of the present studies contribute substantially to articulating these two perspectives. Study 1 suggests that the CSC model may be applicable to the domain of disease threat. We documented an awareness and a divergence stage. In Study 2, people feeling averse to germs and supporting a hierarchical view of society attributed human cases of disease threat to more foreign countries. We discuss implications of these findings and limitations of our study.

\section{Implications for CSC}

The CSC model is applicable to the domain of emerging infectious diseases. This domain and the original CSC domain of biotechnology are similar in that they involve complex and controversial scientific knowledge that is potentially threatening to the established social order. However, while our findings converge with previous studies on CSC, there are also important differences. We found evidence for CSC stages of awareness and divergence in media coverage of the AI outbreak. But unlike Wagner et al. (2002), we could not observe a convergence or normalization stage. There may be several reasons for this. First, it may have been too soon to observe them. As a new disease, AI may not have had time to converge and normalize in the media. Alternatively, AI may have entered a paradoxical normalization stage. This term has been used (Rosenbrock et al., 2000; Setbon, 2000) for AIDS to describe the discrepancy between the public's perception of risks and the epidemiological reality of the disease. Current medical treatments have transformed AIDS from a predicted catastrophe into 'a problem that can be managed by public health and medical care' (Rosenbrock et al., 2000, p. 1608), leading to decreased risk perceptions. AI is arguably in a similar situation: a predicted catastrophe (a pandemic) has failed to materialize, thus leading to a decreased perception of risk in the public and in the media. This situation may have been exacerbated by the repetition of this scenario during the $2009 \mathrm{H} 1 \mathrm{~N} 1$ ('swine flu') outbreak, which also was announced as a potential catastrophe (indeed, a pandemic was eventually declared by the WHO) but turned out 
to be relatively mild. Moreover, the relative frequency at which new infectious diseases occur may also explain why normalization is hard to detect. Representations of previous diseases may be used to anchor understanding of a newly emerging infectious disease in the awareness stage. This difference in findings indicates that more research on different cases of CSC from various domains is necessary to refine the model and better specify the characteristics and variability of the stages. We suggest adopting a case-study approach, analysing dynamics, and contextual aspects of the relation between a specific collective threat and CSC processes. More cases should enable theory building by crosscase comparisons (Eisenhardt, 1989), thus leading to further specification of the CSC model. Such comparisons would allow answering the question whether CSC stages as currently described are specific to events such as disease outbreaks or whether they are a common feature of suddenly occurring threats in general. They may also reveal dynamics internal to each stage, for example, how the thematic diversity and multiplicity of frames postulated to characterize the divergence phase emerges over time.

\section{Implications for othering}

Our study has implications for the study of othering as a response to disease threat. We have shown that a particular combination of individual differences in perceived vulnerability to disease (more particularly GA), ideological beliefs about group hierarchies (SDO), and media context (divergence stage) facilitates the perception of disease threat as located among out-groups such as foreign countries. In other words, othering is more likely during certain moments of an outbreak than others. This conclusion is consistent with work suggesting that categorization and in-group protection strategies can be linked to situational uncertainty (Hogg, 2000). The CSC model and the motivation to reduce uncertainty thus offer an explanation of why inter-group phenomena are likely to occur during this stage. Indeed, out-group blame is often anchored in preexisting representations about out-groups (Joffe \& Staerklé, 2007). These representations provide symbolic material (images, metaphors, and the like) that may be used during the divergence phase to make sense of the novel, threatening event. For example, attributions of poor hygiene can be used both to anchor (Moscovici, 1961) a novel disease outbreak in existing representations (e.g., derogatory representations of lowstatus out-groups) and to objectify (Moscovici, 1961) it by means of concrete images such as nations on a map or pictures of wild birds.

\section{Limitations}

Study 2 used a student sample, which limits the generalization of our results to the population. Due to the university climate promoting anti-discrimination norms, students often have more tolerant worldviews than the general public (Henry, 2008). They may be more reluctant to stigmatize out-groups and probably are more exposed to mass media than some other groups. However, there is no reason to suspect that the underlying psychological mechanisms involved in the three-way interactions would differ between students and the general public. Second, in Study 2, we cannot draw firm causal conclusions concerning the impact of uncertainty (divergence) as this factor was observed but not manipulated. However, we studied CSC, a temporal process that unfolded over several years, which is impossible to manipulate. Thus, the disadvantages of a lack of control over this independent variable are outweighed by the benefits of examining reactions to a real-life health threat. 


\section{Conclusions}

Despite its limitations, our study constitutes an original contribution to understanding how CSC processes and processes of out-group blame (othering) interact. We show that othering is particularly likely during the divergence stage of CSC, when multiple interpretations of a disease coexist, thereby creating a symbolic environment characterized by increased uncertainty. Othering operates to reduce this uncertainty by symbolically associating the disease with out-groups.

\section{Acknowledgements}

This study was supported by a grant from the Swiss National Science Foundation (100014_122366/1). The authors would like to thank Nick Haslam for valuable comments and advice on this paper.

\section{References}

Adam, J. (1989). The HIV myth. New York: St. Martin's Press.

Bauer, M. W. (1998). The medicalisation of science news: From the 'rocket-scalpel' to the 'gene-meteorite' complex. Social Science Information, 37, 731-751. doi:10.1177/ 053901898037004009

Bauer, M. W. (2000). Science in the media as cultural indicator: Contextualizing surveys with media analysis. In M. Dierkes \& C. Von Grote (Eds.), Between understanding and trust: the public, science and technology (pp. 157-178). Amsterdam: Routledge.

Duncan, L. A., Schaller, M., \& Park, J. H. (2009). Perceived vulnerability to disease: Development and validation of a 15-item self-report instrument. Personality and Individual Differences, 37 , 541-546. doi:10.1016/j.paid.2009.05.001

Eisenhardt, K. M. (1989). Building theories from case study research. Academy of Management Review, 14, 532-550. doi:10.2307/258557

Faulkner, J., Schaller, M., Park, J. H., \& Duncan, L. A. (2004). Evolved disease-avoidance mechanisms and contemporary xenophobic attitudes. Group Processes and Intergroup Relations, 7, 333353. doi: $10.1177 / 1368430204046142$

Goertzel, T. (1994). Belief in conspiracy theories. Political Psychology, 15, 733-744. doi:10.2307/ 3791630

Green, E. G. T., Krings, F., Staerklé, C., Bangerter, A., Clémence, A., Wagner-Egger, P., \& Bornand, T. (2010). Keeping the vermin out: Perceived disease threat and ideological orientations as predictors of exclusionary immigration attitudes. Journal of Community and Applied Social Psychology, 20, 299-316. doi:10.1002/casp.1037

Grieve, P., \& Hogg, M. A. (1999). Subjective uncertainty and intergroup discrimination in the minimal group situation. Personality and Social Psychology Bulletin, 25, 926-940. doi:10. $1177 / 01461672992511002$

Halioua, B. (2004). Histoire de la médecine. [History of medicine]. Paris: Masson.

Henry, P. J. (2008). College sophomores in the laboratory redux: Influences of a narrow data base on social psychology's view of the nature of prejudice. Psychological Inquiry, 19, 49-71. doi:10.1080/10478400802049936

Hibino, A., \& Nagata, M. (2006). Biotechnology in the Japanese media: Comparative analysis of newspaper articles on genetic engineering between Japan and Europe. Asian Journal of Social Psychology, 9, 12-23. doi:10.1111/j.1467-839X.2006.00176.x

Hogg, M. A. (2000). Subjective uncertainty reduction through self-categorization: A motivational theory of social identity processes. European Review of Social Psychology, 11, 223-255. doi:10.1080/14792772043000040 
Hohman, Z. P., Hogg, M. A., \& Bligh, M. C. (2010). Identity and intergroup leadership: Asymmetrical political and national identification in response to uncertainty. Self and Identity, 9, 113-128. doi:10.1080/15298860802605937

Joffe, H. (1999). Risk and the "other". Cambridge: Cambridge University Press.

Joffe H., \& Bettega, N. (2003). Social representation of AIDS among Zambian adolescents. Journal of Health Psychology, 8, 616-31. doi:10.1177/13591053030085011

Joffe, H., \& Haarhoff, G. (2002). Representations of far-flung illnesses: The case of Ebola in Britain. Social Science and Medicine, 54, 955-969. doi:10.1016/S0277-9536\%2801\%2900068-5

Joffe, H., \& Lee, N. Y. L. (2004). Social representation of a food risk: The Hong Kong avian bird flu epidemic. Journal of Health Psychology, 9, 517-533. doi:10.1177/1359105304044036

Joffe, H., \& Staerklé, C. (2007). The centrality of the self-control ethos in Western aspersions regarding outgroups: A social representational analysis of common stereotype content. Culture and Psychology, 13, 395-418. doi:10.1177/1354067X07082750

Kalichman, S. C. (2009). Denying AIDS: conspiracy theories, pseudoscience, and buman tragedy. New York: Springer/Copernicus Books.

Kelly, J. (2005). The Great Mortality: An intimate history of the Black Death, the most devastating plague of all time. New York: Harper Collins.

Kimmel, A. J., \& Keefer, R. (1991). Psychological correlates of the acceptance and transmission of rumors about AIDS. Journal of Applied Social Psychology, 21, 1608-1628. doi:10.1111/j. 1559-1816.1991.tb00490.x

Klein, O., \& Licata, L. (2003). When group representations serve social change: The speeches of Patrice Lumumba during the Congolese decolonization. British Journal of Social Psychology, 42, 571-593. doi:10.1348/014466603322595284

Krings, F., Green, E. G. T., Bangerter, A., Staerklé, C., Clémence, A., Wagner-Egger, P., \& Bornand, T. (in press). Preventing contagion with avian influenza: Disease salience, attitudes toward foreigners, and avoidance beliefs. Journal of Applied Social Psychology.

Kronberger, N., \& Wagner, W. (2000). Keywords in context: The statistical analysis of text and open-ended responses. In G. Gaskell \& M. Bauer (Eds.), Methods for qualitative analysis (pp. 299-317). London: Sage.

Kurzban, R., \& Leary, M. R. (2001). Evolutionary origins of stigmatization: The functions of social exclusion. Psychological Bulletin, 127, 187-208. doi:10.1037/0033-2909.127.2.187

Lazarus, R. S., \& Folkman, S. (1984). Stress, appraisal and coping. New York: Springer.

McCombs, M. E. (1981). The agenda-setting approach. In D. Nimmo \& K. Sanders (Eds.), Handbook of political communication (pp. 121-140). Beverly Hills: Sage.

Moscovici, S. (1961). La psychanalyse, son image et son public. [Psychoanalysis, its image and its public]. Paris: Presses Universitaires de France.

Moscovici, S. (1988). Notes towards a description of social representations. European Journal of Social Psychology, 18, 211-250. doi:10.1002/ejsp.2420180303

Mullin, B. A., \& Hogg, M. A. (1999). Motivation for group membership: The role of subjective importance and uncertainty reduction. Basic and Applied Social Psychology, 21, 91-102. doi:10.1207/15324839951036443

Navarrete, C. D., \& Fessler, D. M. T. (2006). Disease avoidance and ethnocentrism: The effects of disease vulnerability and disgust sensitivity on intergroup attitudes. Evolution and Human Behavior, 27, 270-282. doi:10.1016/j.evolhumbehav.2005.12.001

Park, J. H., Faulkner, J., \& Schaller, M. (2003). Evolved disease-avoidance processes and contemporary anti-social behavior: Prejudicial attitudes and avoidance of people with physical disabilities. Journal of Nonverbal Behavior, 27, 65-87. doi:10.1023/A:1023910408854

Peterson, B. E., Duncan, L. E., \& Pang, J. S. (2002). Authoritarianism and political impoverishment: Deficits in knowledge and civic disinterest. Political Psychology, 23, 97-112. doi:10.1111/ 0162-895X.00272

Pratto, F., Sidanius, J., Stallworth, L. M., \& Malle, B. F. (1994). Social dominance orientation: A personality variable predicting social and political attitudes. Journal of Personality and Social Psychology, 67, 741-763. doi:10.1037/0022-3514.67.4.741 
Reid, S. A., \& Hogg, M. A. (2005). Uncertainty reduction, self-enhancement, and in-group identification. Personality and Social Psychology Bulletin, 31, 804-817. doi:10.1177/ 0146167204271708

Reinert, M. (1996). Alceste (Version 3.0). Toulouse, France: Images.

Rosenbrock, R., Dubois-Arber, F., Moers, M., Pinell, P., Schaeffer, D., \& Setbon, M. (2000). The normalization of AIDS in Western European countries. Social Science and Medicine, 50, 16071629. doi: $10.1016 / \mathrm{S} 0277-9536 \% 2899 \% 2900469-4$

Schaller, M., Faulkner, J., Park, J. H., Neuberg, S. L., \& Kenrick, D. T. (2004).Impressions of danger influence impressions of people: An evolutionary perspective on individual and collective cognition. Journal of Cultural and Evolutionary Psychology, 2, 231-247. doi:10.1556/JCEP. 2.2004.3-4.4

Schonhardt-Bailey, C. (2005). Measuring ideas more effectively: An analysis of Bush and Kerry's national security speeches. Political Science and Politics, 38, 701-711.

Setbon, M. (2000). La normalisation paradoxale du sida [The paradoxical normalization of AIDS]. Revue Française de Sociologie, 41, 61-78. doi:10.1016/S0277-9536\%2899\%2900469-4

Sidanius, J., \& Pratto, F. (1999). Social dominance: An intergroup theory of social hierarchy and oppression. New York: Cambridge University Press.

Sontag, S. (1989). AIDS and its metaphors. New York: Farrar, Straus and Giroux.

Turner, J. C., Hogg, M. A., Oakes, P. J., Reicher, S., \& Wetherell, M. S. (1987). Rediscovering the social group: A self-categorization theory. Oxford: Basil Blackwell.

Tversky, A., \& Kahneman, D. (1973). Availability: A heuristic for judging frequency and probability. Cognitive Psychology, 5, 207-232. doi:10.1016/0010-0285\%2873\%2990033-9

Wagner-Egger, P., Bangerter, A., Gilles, I., Green, E. G. T., Rigaud, D., Krings, F., . ., Clémence, A. (2011). Lay perceptions of collectives at the outbreak of the H1N1 epidemic: Heroes, villains and victims. Public Understanding of Science, 20, 461-476. doi:10.1177/0963662510393605

Wagner, W., \& Hayes, N. (2005). Everyday discourse and common sense: The theory of social representations. Basingstoke: Palgrave Macmillan.

Wagner, W., Kronberger, N., \& Seifert, F. (2002). Collective symbolic coping with new technology: Knowledge, images and public discourse. British Journal of Social Psychology, 41, 323-343. doi:10.1348/014466602760344241

Washer, P. (2004). Representations of SARS in the British newspapers. Social Science and Medicine, 59, 2561-2571. doi:10.1016/j.socscimed.2004.03.038

Received I 7 June 2010; revised version received 20 May 201 I 